This is a post-peer-review, pre-copyedit version of an article published in Current Opinion in Plant Biology. The final authenticated version is available online at: https://doi.org/https://doi.org/

\title{
Endoreplication as a potential driver of cell wall modifications
}

Rahul Bhosale ${ }^{1,2}$, Steven Maere ${ }^{3-5}$ and Lieven De Veylder ${ }^{3,4}$

\section{Addresses}

${ }^{1}$ Plant and Crop Sciences, School of Biosciences, University of Nottingham, Nottingham, LE12 5RD, United Kingdom

${ }^{2}$ Center for Plant Integrative Biology (CPIB), University of Nottingham, Sutton Bonington LE12 5RD, United Kingdom

${ }^{3}$ Department of Plant Biotechnology and Bioinformatics, Ghent University, Ghent, B-9052, Belgium

${ }^{4}$ VIB Center for Plant Systems Biology, Ghent, B-9052, Belgium

${ }^{5}$ Bioinformatics Institute Ghent, Ghent University, Ghent, B-9052, Belgium

Corresponding author: De Veylder, Lieven (lieven.deveylder@psb.vib-ugent.be)

Mailing address: Lieven De Veylder

Center for Plant Systems Biology

VIB-Ghent University

Technologiepark 71

B-9052 Gent (Belgium)

Tel. +32 9 3313961;

Fax: +32 93313809 ;

E-mail: lieven.deveylder@psb.ugent.be

E-mail addresses: rahul.bhosale@nottingham.ac.uk

steven.maere@psb.vib-ugent.be

\section{Highlights}

- A DNA endoploidy map of the Arabidopsis root reveals a strict spatio-temporal regulation of endoreplication.

- Endoreplication is prominent in tissues that require a rapid increase in cell wall materials, such as root hairs and xylem.

- Endoreplication-dependent cell wall modifications might account for the pathogen sensitivity of ploidy mutants.

- Endocycle onset correlates with expression of cell wall-modifying genes that drive cell expansion. 


\begin{abstract}
Endoreplication represents a variant of the mitotic cell cycle during which cells replicate their DNA without mitosis and/or cytokinesis, resulting in an increase in the cells' ploidy level. This process is especially prominent in higher plants, where it has been correlated with cell differentiation, metabolic output and rapid cell growth. However, different reports argue against a ploidy-dependent contribution to cell growth. Here, we review accumulating data suggesting that endocycle onset might exert an effect on cell growth through transcriptional control of cell wall-modifying genes to drive cell wall changes required to accommodate turgor-driven rapid cell expansion, consistent with the idea that vacuolar expansion rather than a ploidy-driven increase in cellular volume represents the major force driving cell growth.
\end{abstract}

\title{
Introduction
}

During a mitotic cell cycle, each round of DNA synthesis is followed by mitosis and cytokinesis to equally distribute the duplicated DNA among two daughter cells. In contrast, during an endocycle (also known as endoreplication), mitosis and/or cytokinesis are skipped, resulting in an increase of the cell's DNA content from $2 \mathrm{C}$ to $4 \mathrm{C}, 8 \mathrm{C}, 16 \mathrm{C}, \ldots$. While this process is widespread across different kingdoms, endoreplication is especially prominent in higher plants, where endocycle activity has been correlated with cell differentiation, increased metabolic output and rapid cell growth $[1,2]$. It is anticipated that the latter processes benefit from an increase in RNA transcription through an increase in gene templates. Accordingly, Bourdon, et al. [3] provided quantitative evidence in tomato fruits that endopolyploidy increases transcription of rRNA and mRNA on a per-nucleus basis.

The most frequently reported effect of endoploidy is its effect on cell size, illustrated in Arabidopsis by the observed correlation between the DNA ploidy level and the size of epidermal pavement cells and trichomes $[4,5]$. However, the relationship between cell size and DNA ploidy level is not that clear, as both pavement cells and trichomes grow as well when endoreplication is severely inhibited $[6,7]$. Correspondingly, dynamic mapping of endocycle onset in Arabidopsis epidermal sepal cells not only revealed that the differences in cell size between cells with a different ploidy level correlate with a variability in the timing of the exit from the mitotic cell cycle, but also that endocycling cells are mainly bigger because they grow without being halved by division [8], arguing against a ploidy-dependent control of cell growth rates. Moreover, the relationship between cell volume and ploidy appears to be tissue-specific, because a strong correlation between both was found for leaf epidermal pavement cells, but not for the palisade mesophyll cells [9•]. Likewise, based on analysis of the tomato pericarp, Bourdon, et al. [10] suggested that cell size is not only dependent on ploidy levels but also on the 
position of the cell within the tissue. Therefore, to understand the role of the endocycle, and in particular its relationship to cell size, it might be important to have a clear view on the spatiotemporal distribution of endoploidy across a complete organ. Experimentally, this can be achieved through cytological techniques such as DNA densitometry or fluorescent in situ hybridization, combining microscopy with image analysis of quantitatively labeled nuclei [9-12].

\section{A virtual root ploidy map}

Although being highly informative, DNA densitometry and fluorescent in situ hybridization are rather laborious techniques and of too low throughput to be easily applied on a complete organ. Recently, a computational approach has been used to overcome these challenges and to map the DNA ploidy distribution across the complete Arabidopsis root tip [13••]. Within the root, all cells arise linearly from a group of stem cells surrounding the quiescent center ( $Q C$ ). Close to the $Q C$, cells are dividing. As cells age, they gradually lose their division competence and gain the possibility to enter the endocycle, resulting in cells having a 4C, 8C, or 16C DNA content. To address how cells with a different ploidy level are integrated into the Arabidopsis root, first the transcriptome of cortex cells with different ploidy levels was determined. Subsequently, the obtained ploidy-dependent expression data of each Arabidopsis gene was used to pinpoint which genes in the dataset have a spatiotemporal expression profile that might be useful to predict the tissue- and development-dependent endoploidy state of every cell within the root. To this end, a mathematical model was built to predict the expression level of a gene in 12 different developmental stages and 17 different tissue marker lines (corresponding to 14 different tissues) as a function of its measured ploidy-specific expression levels in the cortex and the (unknown) ploidy transition boundaries in the different tissues along the longitudinal root axis (Figure 1a). The optimal ploidy boundaries were subsequently estimated by fitting modelled expression for a given gene to the spatiotemporal expression values previously obtained experimentally through transcriptome analysis [14]. Except for genes exhibiting trivial expression profiles with low variance across tissues and developmental stages, a good fit can only be expected for genes for which the ploidy-specific expression levels measured in the cortex cells are a good proxy for the ploidy-specific expression levels in other tissues, and for which the spatiotemporal expression levels are primarily determined by the endoploidy state of the cell, and thus not by tissue- or developmental stage-related factors acting independently of endoploidy. Eventually, 332 of the bestfitting genes, with 83 peaking at each of the endoploidy levels $2 C, 4 C, 8 C$ and $16 C$, were selected as ploidy markers to construct a virtual endoploidy map for the complete root tip. The marker gene list was significantly enriched in genes functioning in biological processes related to DNA replication and epigenetic regulation of gene expression, which are arguably more likely to exhibit absolute expression 
levels linked to DNA content. The predicted endoploidy map, which was subsequently experimentally validated, revealed that endoreplication is under strict spatiotemporal control, showing an overall concentric pattern with the ground tissues displaying higher endoreplication activity and the inner vascular tissues mostly being of lower ploidy (Figure 1b).

\section{Causal links between cell ploidy and cell wall characteristics}

The obtained ploidy map revealed that within the epidermis, hair cells undergo one extra round of endoreplication compared to non-hair cells, reaching a maximum ploidy level of $16 \mathrm{C}$ as opposed to $8 \mathrm{C}$ for non-hair cells (Figure 1b). This observation suggests that endoreplication might support hair tip growth. However, up to date, it is unclear whether endoreplication is a prerequisite for root hair growth. For the midget and rh/1/hyp7 mutants that are defective in the DNA topoisomerase VI complex, which is essential for decantation of replicated chromosomes, the inability to progress beyond an $8 \mathrm{C}$ ploidy level has been found to correlate with a root hair tip outgrowth phenotype $[15,16]$ (Figure 2). In contrast, E Sliwinska et al. [17] reported that there is no clear correlation between the length of collet hair cells (hairs arising at the transition zone between the root and hypocotyl) and the level of endoreplication across a diverse set of mutants studied, with the short root hair ethylene overproducer 1 (eto1) mutant accumulating even a higher ploidy level. A possible explanation for this apparent contradiction is that the replication factors MIDGET and RHL1/HYP7 likely directly affect the endoreplication process, whereas the hormone mutant eto 1 might indirectly exert a growth effect independent of the endocycle. Therefore, experiments aiming at a more direct manipulation of the endocycle might be required to draw any conclusions on the role of the endocycle in root hair tip growth.

A putative scenario by which the endocycle might contribute to root hair tip growth is by providing the increased metabolic output needed for root hair tip outgrowth. Rapidly expanding root hairs express unique cell expansion and cell wall-modifying enzymes [18]. But root hair cells are not the only cells that demand a rapid increase in the production of cell wall materials, so do the xylem cells. Maturing xylem cells develop a thick secondary cell wall to provide the mechanical strength needed for transport of water and nutrients. The ploidy map revealed that, next to epidermal hair cells, xylem cells rapidly engage into the endocycle, in contrast to the phloem and phloem companion cells that mainly remain diploid. Strikingly, the endocycle-promoting kaktus mutation has been identified as a suppressor of the esk1-5 mutation [19]. ESK1 encodes a xylan O-acetyltransferase and its mutation results in collapsed xylem vessels [20]. The observation that a ploidy-inducing mutation can rescue this phenotype again suggests a role of endocycle-driven gene expression in controlling cell wall biosynthesis. 
A link between endoploidy and cell wall modification might also explain the observed altered pathogen response of ploidy mutant lines. Modification of the cell wall at sites of pathogen attack is a common response to infection $[21,22]$ and the inability to do so, or the presence of a weakened cell wall, might explain in part the pathogen susceptibility phenotypes of endocycle onset mutants, such as observed for smr1 and sim smr1 [23,24] (Figure 2). Likewise, ectopic overexpression of the endocycle-promoting UVI4 and OSD1 genes (see Textbox on molecular control of endocycle onset) results in enhanced disease resistance $[25,26]$. Strikingly, a transcriptome analysis revealed that $90 \%$ of the genes upregulated in the CONSITUTIVE EXPRESSION OF PATHOGENESIS-RELATED GENES (cpr5) mutant depend on SIM and SMR1 activity. Moreover, the pathogen resistance phenotype of the cpr5 mutant is restored in the cpr5 sim smr1 triple mutant [24], suggesting that SIM and SMR1 are directly responsible for endoploidy-dependent pathogen defense. Accordingly, transcriptome analysis of SMR1 (also known as LGO1)-overexpressing lines revealed a constitutively activated defense response [27]. In agreement with a role for SIM and SMR proteins in pathogen defense, the rice SIM/SMR homolog EL2 was originally identified as a gene being rapidly and strongly induced upon treatment with a biotic elicitor or flagellin $[28,29]$.

More links between endoploidy and cell wall biosynthesis exist. For instance, the above-mentioned midget mutant not only displays a root hair phenotype but also an altered patterning of its seed coat, a phenotype speculated to be the result of a reduction in the secretion of mucilage, which is mainly composed of the cell wall components rhamnose and galacturonic acid [15]. Similarly, next to a constitutive pathogen response phenotype and reduced DNA content, trichomes of cpr5 mutants display a thinner cell wall and reduced cellulose content [30,31]. Strikingly, cpr5 mutant trichomes display an additional spontaneous cell death phenotype [31], similar to the phenotype observed for trichomes in which endocycle progression is specifically blocked through ectopic expression of the CDK inhibitor KRP1 [6]. A speculative explanation might be that a reduction in ploidy results in insufficient cell wall components being produced to cope with turgor arising from the expanding vacuole, eventually resulting in bursting of the cells.

Interestingly, endoreplication onset precedes rapid cell expansion $[13 \bullet \bullet, 32]$. Within the root, this rapid expansion at the cell division-to-cell expansion border depends on the antagonistic activity of cytokinin and auxin, resulting in an auxin minimum in the topmost meristematic cell [33]. This suggests that a low auxin level might act as a positional signal to trigger the switch from cell division to differentiation. More recently, it has been found that this drop in auxin content goes together with expression of cell wall-modifying genes, in particular encoding the cell wall-loosening expansins and plasma membrane-localised $\mathrm{H}^{+}$-ATPases, together driving $\mathrm{pH}$-dependent cell wall modifications, 
further driving rapid cell elongation [34]. The observation that auxin represses endocycle onset $[13 \bullet \bullet, 35]$ suggests that endoreplication might contribute to such cell wall modifications. In support for this hypothesis, comparing the transcriptome of expanding wild-type versus smr1 mutant cells revealed a correlation between endocycle onset, upregulation of specific cell wall-modifying genes, including xylan biosynthesis genes, and downregulation of $D E L 3$, which encodes a transcriptional repressor of expansin genes and an UDP-glucose-glycosyl transferase $[13 \bullet \bullet, 36]$.

Ploidy-driven cell wall changes might not be restricted to endoploidy changes but might be generally related to polyploidization. When examining Arabidopsis plants with different somatic ploidy levels $(2 \mathrm{~N}, 4 \mathrm{~N}, 6 \mathrm{~N}$ and $8 \mathrm{~N})$, the ploidy level was found to be negatively correlated with lignin and cellulose abundance and positively with matrix polysaccharide content (hemicellulose and pectin) [37]. Interestingly, cross sections revealed that the shape of stem cortical cells was distorted in the highploidy plants, with cell walls being highly distorted and reduced in thickness. More specifically, stems of hexa- and octaploid plants appeared to be completely crushed, indicating that the strength of the cell walls was affected in the polyploid lines and again hinting to a link between ploidy and the cell wall characteristics. Correspondingly, transcriptome comparison of diploid versus tetraploid Col-0 plants revealed a limited set of differentially expressed genes, enriched for cell wall biosynthesis genes [38], whereas diploid and tetraploid etiolated hypocotyls were found to differ in permeability of the cuticle layer, an epidermal protective, hydrophobic waxy covering against pathogen attack and water loss [39]. Similarly, when comparing the mRNA transcriptome of diploid, tetraploid and octoploid plants, it was found that the absolute transcript levels of most genes scale with ploidy. Nevertheless, one cluster of genes showed a linear increase in expression per gene copy with increasing ploidy, and this cluster was found to be enriched for cell wall functions [40]. Therefore, it appears that similar to endoploidy, somatic ploidy might translate into cell wall changes, although currently it cannot be excluded that these changes represent indirect transcriptional responses that occur in reaction to changes in cytoplasmic versus cellular volume [40].

\section{Conclusions}

Although currently mainly supported by circumstantial data, recent reports suggest that endocycle onset may regulate the expression of cell wall-modifying genes to drive cell wall changes, presumably to prepare cells for the often massive cell enlargement following cell cycle exit. This is in line with the idea that vacuolar expansion likely represents the major force driving cell growth, rather than a ploidydriven increase in cellular volume [41]. Likewise, recently a second mode of rapid root cell elongation was described as being dependent on actin dynamics but independent of endoreplication [42]. Indeed, plant cells in which endoreplication is impaired are still able to expand $[6,7]$, indicating only a minor 
contribution of the endocycle to growth compared to vacuolar expansion and actin reorganization. In the case of vacuole-driven cell expansion, the balance between the turgor generated by the vacuole and the strength of the cell wall determines the rate of cell growth. In this scenario, the endocycle could serve to modulate cell expansion by regulating the strength of the cell wall by stimulating the expression of both cell wall loosening and fortifying genes (Figure 3). Therefore, the endocycle might be of particular importance for tissues containing extremely rapidly expanding cells, where an increase in the gene copy number through endoreplication might be a way to cope with the high demand for new cell wall materials.

Seen the role of the cell wall in many biotic and abiotic responses, endoreplication-induced cell wall changes might also play an important role in adaptive stress responses. This may explain why the endocycle is mainly observed in species growing in variable environments $[43,44]$. How the endocycle specifically controls expression of cell wall biosynthesis and cell wall-modifying genes remains to be further elucidated. Results from the field of rhizobiology suggest a role for epigenetic reprogramming. Using nodule nuclei sorted according to their DNA content, a correlation between ploidy level, gene expression, and chromatin structure has been found [45]. In accordance, a high number of chromatinrelated genes were found to be differentially expressed in wild-type versus smr1 mutant plants [13], correlated with altered histone dynamics upon exit of the mitotic cell cycle [46]. Revealing the genetic network that accounts for reprogramming of the transcriptome in response to altered ploidy levels therefore represents a major future challenge.

\section{Acknowledgements}

The authors thank Annick Bleys and Jefri Heyman for help in preparing the manuscript and figures, respectively. This work was supported by grants of the Research Foundation-Flanders (G.023616N) and University of Nottingham Future Food Beacon of Excellence Nottingham Research. 


\section{Textbox 1: Simplified molecular toolbox controlling endocycle onset}

The molecular machinery driving endoreplication has been mainly studied in Arabidopsis, revealing a number of pathways seemingly operating in parallel and triggering endocycle onset by suppressing the abrupt rise in cyclin-dependent kinase (CDK) activity that is needed to trigger mitosis and cytokinesis. CDK inactivation is either achieved through association of the CDK subunit with inhibitory proteins or through preventing the accumulation of the cyclins that are rate-limiting for the G2-to-M transition, controlled by the SIM/SMR and CCS52A proteins, respectively. Biochemical and genetic data suggest that the SIM and SMR (mainly SMR1, also known as LGO1) proteins controlling endocycle onset target the G2/M phase-specific B1-type CDKs (CDKB1;1 and CDKB1;2) [47,48]. Although these SIM and SMR proteins bind as well to the more generic CDKA;1 kinase [47], recent data suggest that CDKA;1 might control SIM/SMR abundance post-transcriptionally by targeting phosphorylated SIM and SMR proteins for proteolytic turnover [49••].

Two other pathways operate through the Anaphase Promoting Complex/Cyclosome (APC/C), a multisubunit E3 ubiquitin ligase complex targeting cell cycle proteins for destruction. Among these targets, the CDKB1;1-interacting cyclin CYCA2;3 has been best characterised in the context of endocycle onset [50]. Both pathways rely on a rate-limiting factor for APC/C activity, known as CCS52A1 and CCS52A2. These factors appear to control endocycle onset in a tissue-specific manner, with CCS52A1 being the main controller in the root elongation zone and trichomes, whereas both CCS52A1 and CCS52A2 contribute to endocycle onset in the leaf [51•]. CCS52A levels are controlled at multiple levels, including transcriptional repression of CCS52A2 by the DEL1 transcription factor [52] and posttranscriptional control of CCS52A1 through the APC/C inhibitor UVI4 [53] and the UBIQUITIN-SPECIFIC PROTEASE 14 [54]. DEL1 itself is controlled by two counteracting E2F transcription factors (E2FB and E2FC) operating as transcriptional activator and repressor, respectively [55]. Both CCS52A1 and CCS52A2 transcription is further restrained in dividing cells through the repressive RBR1-E2FA complex [56]. Additionally, a rise in CCS52A1 activity appears to control an increase in CCS52A2 transcription through a yet unknown mechanism [51•].

More recently, the LATE MERISTEM IDENTITY (LMI) homeobox domain protein has been demonstrated to prevent the development of a stipule (a leaf-like outgrowth) into a leaf through stimulating endocycle onset. This process was speculated to be controlled through transcriptional activation of the WEE1 kinase that inhibits CDK activity through phosphorylation [57••], a mechanism described before to control endocycle onset in tomato [58]. This might represent yet another pathway 
controlling endocycle onset, however probably operating in a tissue-specific manner, as WEE1 was demonstrated before not to control endocycle onset in the Arabidopsis leaf [59] (Figure I).

\section{References}

Papers of particular interest, published within the period of review, have been highlighted as:

- of special interest

-• of outstanding interest

1. De Veylder L, Larkin JC, Schnittger A: Molecular control and function of endoreplication in development and physiology. Trends Plant Sci 2011, 16:624-634.

2. Edgar BA, Zielke N, Gutierrez C: Endocycles: a recurrent evolutionary innovation for postmitotic cell growth. Nat Rev Mol Cell Biol 2014, 15:197-210.

3. Bourdon M, Pirrello J, Cheniclet C, Coriton O, Bourge M, Brown S, Moïse A, Peypelut M, Rouyère $\mathrm{V}$, Renaudin J-P et al:: Evidence for karyoplasmic homeostasis during endoreduplication and a ploidy-dependent increase in gene transcription during tomato fruit growth. Development 2012, 139:3817-3826.

4. Melaragno JE, Mehrotra B, Coleman AW: Relationship between endopolyploidy and cell size in epidermal tissue of Arabidopsis. Plant Cell 1993, 5:1661-1668.

5. Hülskamp M: Plant trichomes: a model for cell differentiation. Nature Reviews Molecular Cell Biology 2004, 5:471-480.

6. Schnittger A, Weinl C, Bouyer D, Schöbinger U, Hülskamp M: Misexpression of the cyclindependent kinase inhibitor ICK1/KRP1 in single-celled Arabidopsis trichomes reduces endoreduplication and cell size and induces cell death. Plant Cell 2003, 15:303-315.

7. De Veylder L, Beeckman T, Beemster GTS, Krols L, Terras F, Landrieu I, Van Der Schueren E, Maes S, Naudts $M$, Inzé D: Functional analysis of cyclin-dependent kinase inhibitors of Arabidopsis. Plant Cell 2001, 13:1653-1667.

8. Roeder AHK, Chickarmane V, Cunha A, Obara B, Manjunath BS, Meyerowitz EM: Variability in the control of cell division underlies sepal epidermal patterning in Arabidopsis thaliana. PLOS Biol 2010, 8:e1000367.

9. - Katagiri Y, Hasegawa J, Fujikura U, Hoshino R, Matsunaga S, Tsukaya H: The coordination of ploidy and cell size differs between cell layers in leaves. Development 2016, 143:1120-1125.

The generally assumed correlation between the endoploidy level of a cell and its size is demonstrated to hold true for epidermal pavement cells but not for palisade cells, illustrating that the correlation between both parameters depends on tissue identity. 
10. Bourdon M, Coriton O, Pirrello J, Cheniclet C, Brown SC, Poujol C, Chevalier C, Renaudin J-P, Frangne $\mathrm{N}$ : In planta quantification of endoreduplication using fluorescent in situ hybridization (FISH). Plant J 2011, 66:1089-1099.

11. - Lavrekha VV, Pasternak T, Ivanov VB, Palme K, Mironova VV: 3D analysis of mitosis distribution highlights the longitudinal zonation and diarch symmetry in proliferation activity of the Arabidopsis thaliana root meristem. Plant J 2017, 92:834-845.

This work demonstrates the combined usage of confocal imaging with image processing to map in a tissue-specific manner cell proliferation within the Arabidopsis thaliana root tip.

12. Pasternak T, Haser T, Falk T, Ronneberger O, Palme K, Otten L: A 3D digital atlas of the Nicotiana tabacum root tip and its use to investigate changes in the root apical meristem induced by the Agrobacterium 6b oncogene. Plant J 2017, 92:31-42.

13. •- Bhosale R, Boudolf V, Cuevas F, Lu R, Eekhout T, Hu Z, Van Isterdael G, Lambert GM, Xu F, Nowack MK et al.: A spatiotemporal DNA endoploidy map of the Arabidopsis root reveals roles for the endocycle in root development and stress adaptation. Plant Cell 2018, 30:23302351.

Through the integration of experimental datasets into a mathematical model, a three-dimensional DNA ploidy map for the complete Arabidopsis thaliana root tip was predicted and experimentally verified. The map obtained revealed that the level of endoploidy is to a remarkable extent differentially controlled across the distinct root tissues and their developmental stages.

14. Brady SM, Orlando DA, Lee J-Y, Wang JY, Koch J, Dinneny JR, Mace D, Ohler U, Benfey PN: A high-resolution root spatiotemporal map reveals dominant expression patterns. Science 2007, 318:801-806

15. Kirik V, Schrader A, Uhrig JF, Hulskamp M: MIDGET unravels functions of the Arabidopsis topoisomerase VI complex in DNA endoreduplication, chromatin condensation, and transcriptional silencing. Plant Cell 2007, 19:3100-3110.

16. Sugimoto-Shirasu K, Roberts GR, Stacey NJ, McCann MC, Maxwell A, Roberts K: RHL1 is an essential component of the plant DNA topoisomerase VI complex and is required for ploidydependent cell growth. Proc Natl Acad Sci USA 2005, 102:18736-18741.

17. Sliwinska E, Mathur J, Bewley JD: On the relationship between endoreduplication and collet hair initiation and tip growth, as determined using six Arabidopsis thaliana root-hair mutants. J Exp Bot 2015, 66:3285-3295.

18. Gu F, Nielsen E: Targeting and regulation of cell wall synthesis during tip growth in plants. J Integr Plant Biol 2013, 55:835-846. 
19. Bensussan M, Lefebvre V, Ducamp A, Trouverie J, Gineau E, Fortabat M-N, Guillebaux A, Baldy A, Naquin D, Herbette $S$ et al.: Suppression of dwarf and irregular xylem phenotypes generates low-acetylated biomass lines in Arabidopsis. Plant Physiol 2015, 168:452-463.

20. Lefebvre V, Fortabat M-N, Ducamp A, North HM, Maia-Grondard A, Trouverie J, Boursiac Y, Mouille G, Durand-Tardif M: ESKIMO1 disruption in Arabidopsis alters vascular tissue and impairs water transport. PLOS ONE 2011, 6:e16645.

21. Clay NK, Adio AM, Denoux C, Jander G, Ausubel FM: Glucosinolate metabolites required for an Arabidopsis innate immune response. Science 2009, 323:95-101.

22. Luna E, Pastor V, Robert J, Flors V, Mauch-Mani B, Ton J: Callose deposition: a multifaceted plant defense response. Mol Plant-Microbe Interact 2011, 24:183-193.

23. Hamdoun S, Zhang C, Gill M, Kumar N, Churchman M, Larkin JC, Kwon A, Lu H: Differential roles of two homologous cyclin-dependent kinase inhibitor genes in regulating cell cycle and innate immunity in Arabidopsis. Plant Physiol 2016, 170:515-527.

24. Wang S, Gu Y, Zebell SG, Anderson LK, Wang W, Mohan R, Dong X: A noncanonical role for the CKI-RB-E2F cell-cycle signaling pathway in plant effector-triggered immunity. Cell Host Microbe 2014, 16:787-794.

25. Bao Z, Hua J: Interaction of CPR5 with cell cycle regulators UVI4 and OSD1 in Arabidopsis. PLOS ONE 2014, 9:e100347.

26. Bao Z, Yang H, Hua J: Perturbation of cell cycle regulation triggers plant immune response via activation of disease resistance genes. Proc Natl Acad Sci USA 2013, 110:2407-2412.

27. Schwarz EM, Roeder AHK: Transcriptomic effects of the cell cycle regulator LGO in Arabidopsis sepals. Front Plant Sci 2016, 7:1744.

28. Minami E, Kuchitsu K, He D-Y, Kouchi H, Midoh N, Ohtsuki $Y$, Shibuya N: Two novel genes rapidly and transiently activated in suspension-cultured rice cells by treatment with $\mathbf{N}$ acetylchitoheptaose, a biotic elicitor for phytoalexin production. Plant Cell Physiol 1996, 37:563-567.

29. Peres A, Churchman ML, Hariharan S, Himanen K, Verkest A, Vandepoele K, Magyar Z, Hatzfeld Y, Van Der Schueren E, Beemster GTS et al.: Novel plant-specific cyclin-dependent kinase inhibitors induced by biotic and abiotic stresses. J Biol Chem 2007, 282:25588-25596.

30. Brininstool G, Kasili R, Simmons LA, Kirik V, Hülskamp M, Larkin JC: Constitutive Expressor Of Pathogenesis-related Genes 5 affects cell wall biogenesis and trichome development. $B M C$ Plant Biol 2008, 8:58.

31. Kirik V, Bouyer D, Schöbinger U, Bechtold N, Herzog M, Bonneville JM, Hülskamp M: CPR5 is involved in cell proliferation and cell death control and encodes a novel transmembrane protein. Curr Biol 2001, 11:1891-1895. 
32. Hayashi K, Hasegawa J, Matsunaga S: The boundary of the meristematic and elongation zones in roots: endoreduplication precedes rapid cell expansion. Sci Rep 2013, 3:2723.

33. Di Mambro R, De Ruvo M, Pacifici E, Salvi E, Sozzani R, Benfey PN, Busch W, Novak O, Ljung K, Di Paola L et al.: Auxin minimum triggers the developmental switch from cell division to cell differentiation in the Arabidopsis root. Proc Natl Acad Sci USA 2017, 114:E7641-E7649.

34. Pacifici E, Di Mambro R, Dello loio R, Costantino P, Sabatini S: Acidic cell elongation drives cell differentiation in the Arabidopsis root. EMBO J 2018, 37:e99134.

35. Ishida T, Adachi S, Yoshimura M, Shimizu K, Umeda M, Sugimoto K: Auxin modulates the transition from the mitotic cycle to the endocycle in Arabidopsis. Development 2010, 137:6371.

36. Ramirez-Parra E, López-Matas MA, Fründt C, Gutierrez C: Role of an atypical E2F transcription factor in the control of Arabidopsis cell growth and differentiation. Plant Cell 2004, 16:23502363.

37. - Corneillie S, De Storme N, Van Acker R, Fangel JU, De Bruyne M, De Rycke RM, Geelen DNV, Willats WGT, Vanholme B, Boerjan WA: Polyploidy affects plant growth and alters cell wall composition. Plant Physiol 2019, 179:74-87.

Arabidopsis thaliana plants with a different somatic ploidy level are demonstrated to possess different cell wall characteristics. Among these, a reduction in the lignin content was observed, resulting in an increased saccharification yield.

38. Yu Z, Haberer G, Matthes M, Rattei T, Mayer KFX, Gierl A, Torres-Ruiz RA: Impact of natural genetic variation on the transcriptome of autotetraploid Arabidopsis thaliana. Proc Natl Acad Sci USA 2010, 107:17809-17814.

39. Narukawa H, Yokoyama R, Komaki S, Sugimoto K, Nishitani K: Stimulation of cell elongation by tetraploidy in hypocotyls of dark-grown Arabidopsis seedlings. PLOS ONE 2015, 10:e0134547.

40. •- Robinson DO, Coate JE, Singh A, Hong L, Bush M, Doyle JJ, Roeder AHK: Ploidy and size at multiple scales in the Arabidopsis sepal. Plant Cell 2018, 30:2308-2329.

The work illustrates how whole-genome duplication within the Arabidopsis thaliana sepal contributes to an increase in organ size at the cellular level and elegantly demonstrates that the mRNA transcriptome scales with genome size.

41. Sugimoto-Shirasu K, Roberts K: "Big it up": endoreduplication and cell-size control in plants. Curr Opin Plant Biol 2003, 6:544-553.

42. Takatsuka H, Higaki T, Umeda M: Actin Reorganization Triggers Rapid Cell Elongation in Roots. Plant Physiol 2018, 178:1130-1141.

43. Barow M: Endopolyploidy in seed plants. BioEssays 2006, 28:271-281. 
44. Scholes DR, Paige KN: Plasticity in ploidy: a generalized response to stress. Trends Plant Sci 2015, 20:165-175.

45. Nagymihály, M., Veluchamy A, Györgypál Z, Ariel F, Jégu T, Benhamed M, Szúcs A, Kereszt A, Mergaert $\mathrm{P}$, Kondorosi E: Ploidy-dependent changes in the epigenome of symbiotic cells correlate with specific patterns of gene expression. Proc Natl Acad Sci USA 2017, 114:45434548.

46. - Otero S, Desvoyes B, Peiró R, Gutierrez C: Histone H3 dynamics reveal domains with distinct proliferation potential in the Arabidopsis root. Plant Cell 2016, 28:1361-1371.

Monitoring histone dynamics reveals dramatic changes in abundance of H3.1 and H3.3 at the onset of endoreplication, suggesting that histone H3-dependent chromatin reprogramming accompanies endocycle onset.

47. Kumar N, Harashima H, Kalve S, Bramsiepe J, Wang K, Sizani BL, Bertrand LL, Johnson MC, Faulk C, Dale R et al.: Functional conservation in the SIAMESE-RELATED family of cyclin-dependent kinase inhibitors in land plants. Plant Cell 2015, 27:3065-3080.

48. Van Leene J, Hollunder J, Eeckhout D, Persiau G, Van De Slijke E, Stals H, Van Isterdael G, Verkest A, Neirynck S, Buffel Y et al.: Targeted interactomics reveals a complex core cell cycle machinery in Arabidopsis thaliana. Mol Syst Biol 2010, 6:397.

49. •- Dubois M, Selden K, Bediée A, Rolland G, Baumberger N, Noir S, Bach L, Lamy G, Granier C, Genschik P: SIAMESE-RELATED1 is regulated posttranslationally and participates in repression of leaf growth. Plant Physiol 2018, 176:2834-2850.

This works provides the first molecular proof for the post-transcriptional control of the SIM/SMR cyclin-dependent kinase inhibitors, both through phosphorylation and ubiquitination. Additionally, SMR1 is linked to the growth inhibitory effect triggered by drought stress.

50. Boudolf V, Lammens T, Boruc J, Van Leene J, Van Den Daele H, Maes S, Van Isterdael G, Russinova $E$, Kondorosi $E$, Witters $E$ et al.: CDKB1;1 forms a functional complex with CYCA2;3 to suppress endocycle onset. Plant Physiol 2009, 150:1482-1493.

51. - Heyman J, Polyn S, Eekhout T, De Veylder L: Tissue-specific control of the endocycle by the Anaphase Promoting Complex/Cyclosome inhibitors UVI4 and DEL1. Plant Physiol 2017, 175:303-313.

Through study of negative regulators of the APC/C regulatory proteins CCS52A1 and CCS52A2, it was found that both CCS52A proteins independently coordinate endocycle onset in the root and hair cells, but are interdependent in leaf cells, illustrating a tissue-specific control of APC/C activity.

52. Lammens T, Boudolf V, Kheibarshekan L, Zalmas LP, Gaamouche T, Maes S, Vanstraelen M, Kondorosi E, La Thangue NB, Govaerts W et al.: Atypical E2F activity restrains APC/C CC552A2 function obligatory for endocycle onset. Proc Natl Acad Sci USA 2008, 105:14721-14726. 
53. Heyman J, Van den Daele H, De Wit K, Boudolf V, Berckmans B, Verkest A, Lessa Alvim Kamei C, De Jaeger G, Koncz C, De Veylder L: Arabidopsis ULTRAVIOLET-B-INSENSITIVE4 maintains cell division activity by temporal inhibition of the anaphase-promoting complex/cyclosome. Plant Cell 2011, 23:4394-4410.

54. Xu Y, Jin W, Li N, Zhang W, Liu C, Li C, Li Y: UBIQUITIN-SPECIFIC PROTEASE14 interacts with ULTRAVIOLET-B INSENSITIVE4 to regulate endoreduplication and cell and organ growth in Arabidopsis. Plant Cell 2016, 28:1200-1214.

55. Berckmans B, Lammens T, Van Den Daele H, Magyar Z, Bögre L, De Veylder L: Light-dependent regulation of DEL1 is determined by the antagonistic action of E2Fb and E2Fc. Plant Physiol 2011, 157:1440-1451.

56. Magyar Z, Horváth B, Khan S, Mohammed B, Henriques R, De Veylder L, Bakó L, Scheres B, Bögre L: Arabidopsis E2FA stimulates proliferation and endocycle separately through RBRbound and RBR-free complexes. EMBO J 2012, 31:1480-1493.

57. •• Vuolo F, Kierzkowski D, Runions A, Hajheidari M, Mentink RA, Gupta MD, Zhang Z, Vlad D, Wang Y, Pecinka A et al.: LMI1 homeodomain protein regulates organ proportions by spatial modulation of endoreduplication. Genes Dev 2018, 32:1361-1366.

The homeodomain protein LM1 was demonstrated to restrain stipules from differentiating into leaves through the activation of endoreplication. Endocycle onset is postulated to be achieved through activation of the WEE1 kinase that inhibits CDK activity through phosphorylation.

58. Gonzalez N, Gévaudant F, Hernould M, Chevalier C, Mouras A: The cell cycle-associated protein kinase WEE1 regulates cell size in relation to endoreduplication in developing tomato fruit. Plant J 2007, 51:642-655.

59. De Schutter K, Joubès J, Cools T, Verkest A, Corellou F, Babiychuk E, Van Der Schueren E, Beeckman T, Kushnir S, Inzé D et al.: Arabidopsis WEE1 kinase controls cell cycle arrest in response to activation of the DNA integrity checkpoint. Plant Cell 2007, 19:211-225. 


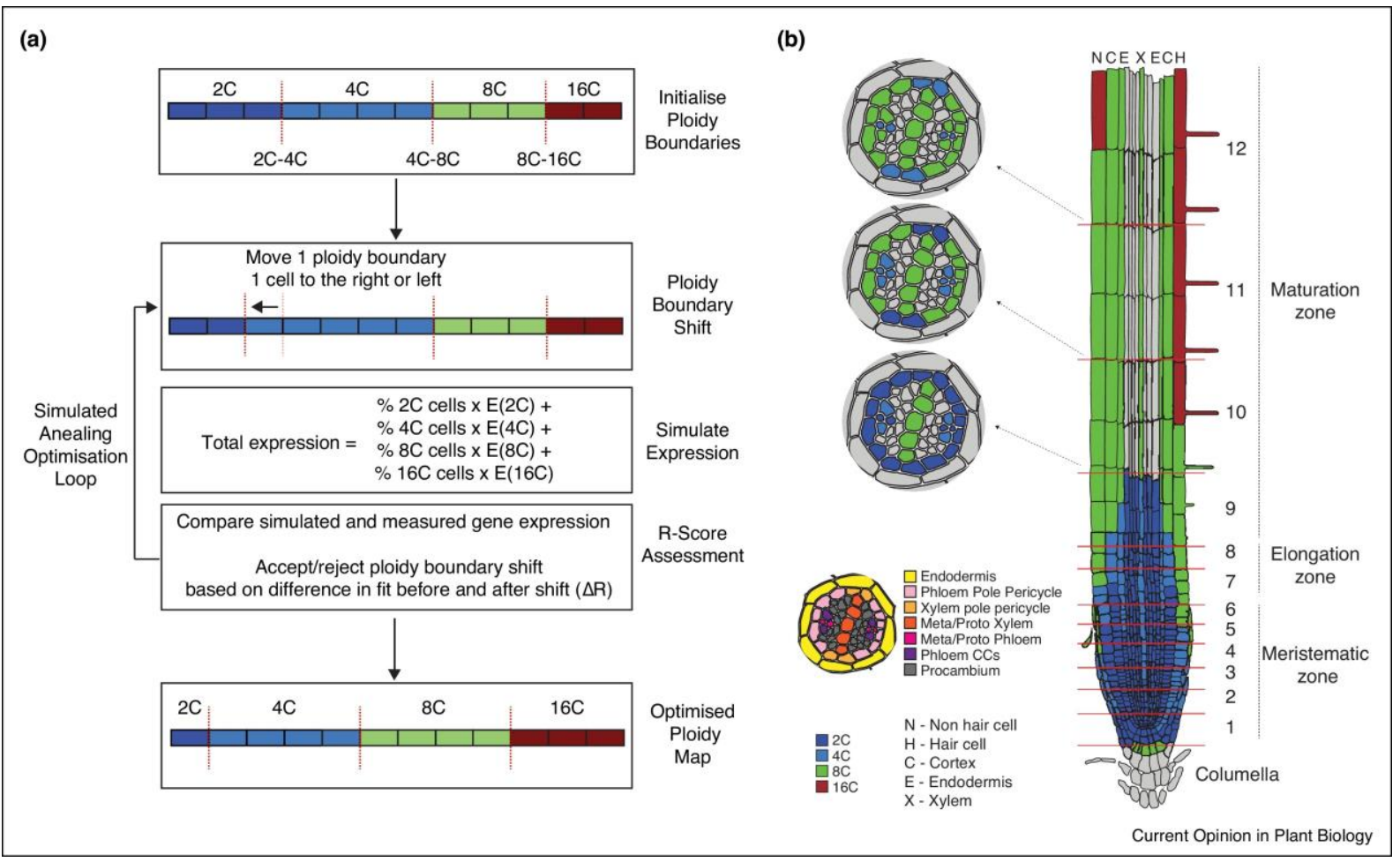

Figure 1. Virtual DNA ploidy map of the Arabidopsis root tip. (a) Simplified schematic representation of the mathematical modelling approach used in Bhosale, et al. [13••]. For simplicity, only one tissue layer is shown here, subdivided into 12 sections. Ploidy boundaries (2C-4C, 4C-8C and 8C-16C) are initially randomly assigned. Subsequently, one of the boundaries is shifted one cell up or down the cell file, and the obtained ploidy pattern is used to calculate a gene's total expression value in the tissue file (simulated expression), using the ploidy-dependent expression values of that particular gene in the root cortex cells. The simulated expression profile is then compared to the expression profile experimentally measured by Brady et al. [14] (R-score assessment) and the proposed boundary shift is accepted or rejected, after which the process is repeated until the best possible fit (low R-score) between the simulated and measured expression levels is obtained, resulting in an optimised ploidy map. (b) Root ploidy map obtained upon simultaneous model optimization for 332 ploidy reporter genes across 14 tissues and 12 root sections. Radial cross sections of slices 10-12 are shown to detail the vascular tissue. Procambium tissue is left unassigned because there is less confidence in the predicted ploidy levels as a result of the unavailability of expression profiles obtained using a specific procambium tissue reporter. 


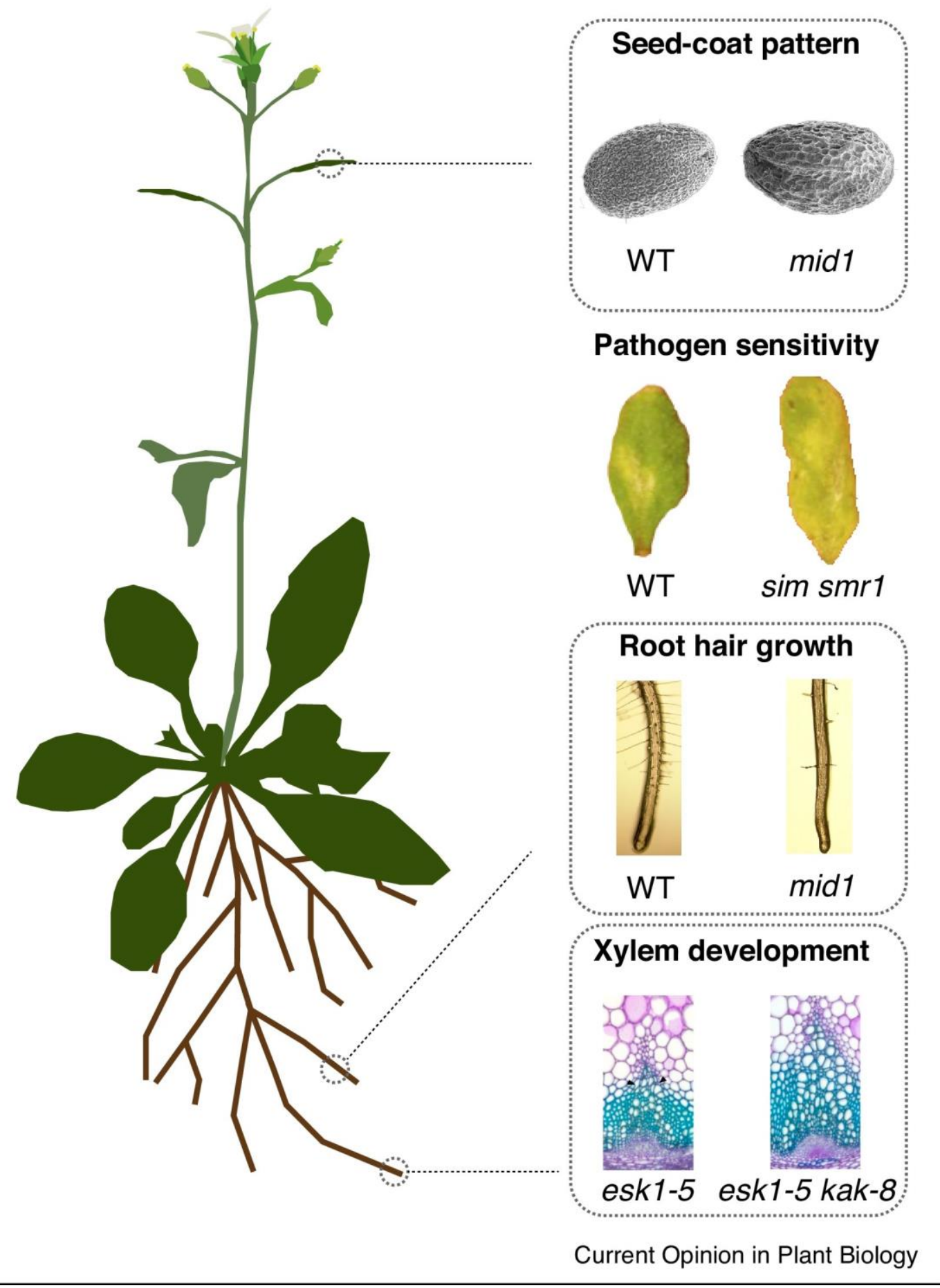

Figure 2. Causal links between endoreplication and cell wall biosynthesis or fortification. A reduced endoploidy level in the mid1 mutant has been found to correlate with altered seed-coat composition and inhibition of root cell tip growth [15], whereas the sim smr1 mutations have been correlated with altered pathogen sensitivity [23]. Reversely, the endocycle promoting kak-8 mutation was found as a suppressor mutation rescuing the xylem vessel esk1-5 mutant phenotype [19]. Part of the figures are reused from [15, 19, 23] (www.plantphysiol.org / www.plantcell.org). Copyright American Society of Plant Biologists. 


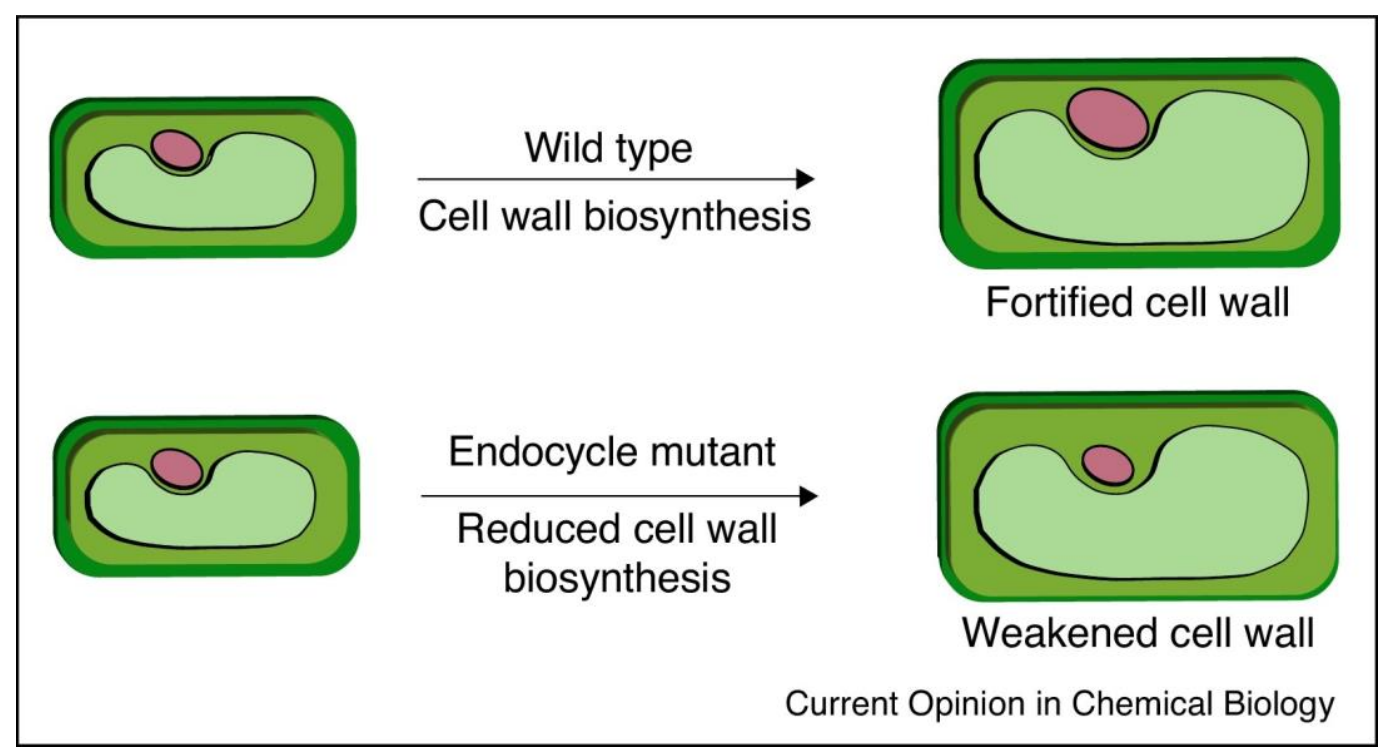

Figure 3. Model for the endocycle contributing to cell wall fortification. When cells stop to divide mitotically, the vacuole (light green) likely represents the major force for growth through exerting turgor pressure on the plasma membrane. We speculate that an increase in nuclear size (pink) through endoreplication helps in supporting such rapid growth with the expression of cell wall biosynthesis and -modifying genes, resulting in a fortified cell wall (dark green) matching the cell's rapid expansion. In endocycle mutants, such cell wall modification might lag behind, resulting in altered cell wall characteristics.

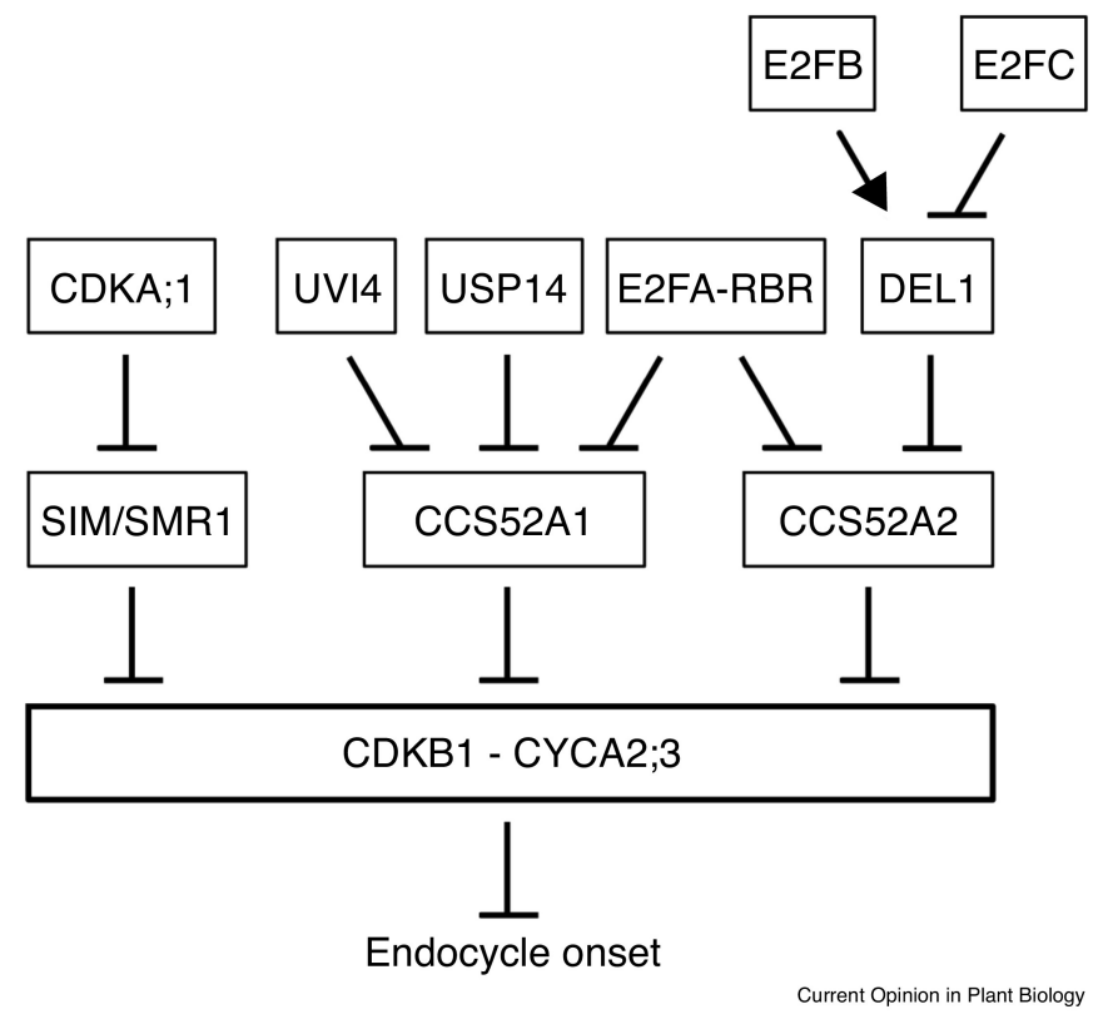

Text Box Figure I. Molecular toolbox of endocycle onset 